\title{
Comment
}

\section{Objections to the use of cost-effectiveness analysis in the US: reflecting on 'Has the time come for cost-effectiveness analysis in US health care?'}

\author{
MICHAEL K. GUSMANO*
}

The Hasting Center, USA

In the midst of the US health care reform debate in 2009, Governor Rick Scott, the founder of the Columbia Hospital Corporation, formed a group called 'conservatives for patient's rights.' The mission of the group was to defeat health reform ideas espoused by the Democrats. On the group's web site, it claimed that President Obama wanted to create 'a national health board similar to the one in Britain that could potentially lead to bureaucrats making health care decisions rather than patients and their doctors' (http://insightonfreedom.blogspot.com/ 2009/03/conservatives-launch-campaign-for-free.html, accessed 20 November 2014). Scott's group was roundly criticized by many for its inaccuracies (Brown, 2009), but its caricature of National Institute for Health and Care Excellence and the suggestion that expanded government involvement in health care would limit access to 'life-saving' technology echoes decades of attacks by conservatives against government involvement in health care. Every effort to expand the use of health technology assessment, particularly efforts to apply cost-effectiveness analysis (CEA) to health care, have been subject to fiery political attacks. Reflecting this political tradition, the Congress prohibited the Patient-Centered Outcomes Research Institute (PCORI) from using dollars-per-quality adjusted life year as a criterion to address the charge that it would ration care. Even though Congress limited PCORI's ability to conduct CEA, the Institute remains controversial and Republicans hope to eliminate it as part of their agenda to undermine the ACA in 2015 and beyond (Demko, 2014).

In their 2009 article, 'Has the time come for cost-effectiveness analysis in US health care?', Stirling Bryan et al. try to better understand the controversial politics of CEA and identify strategies that might make the use of these techniques politically acceptable in the United States. Their findings remind us that framing

"Correspondence to: Michael K. Gusmano, PhD, Research Scholar, The Hasting Center, 21 Malcolm Gordon Road, Garrison, NY 10524, USA. Email: gusmanom@thehastingscenter.org 
and language can have a dramatic effect on policy debates. The fact that CEA is often associated with the word rationing - which is used to evoke fear of inappropriate limits on effective medical technology - creates a political barrier to the use of economic evaluation. Ironically, decision makers are concerned that studies financed by industry might result in the opposite problem. If CEA relies on studies financed by industry, it could lead to the approval and use of drugs and other technologies of limited value. The lack of public trust in private and public institutions may represent an enormous obstacle to the political system's willingness to accept CEA and society's capacity to make difficult policy choices.

\section{CEA and the search for value}

Health care spending has been a continual focus of policy makers in the United States since President Nixon announced that the country faced a health care 'crisis' in 1969. In recent years, however, there has been a subtle shift in the debate over health care spending. Spending a large percentage of societal resources on health care is not necessarily a problem, but spending additional resources on health care that does not appear to generate health benefits is a waste. John Wennberg's pioneering research on small-area variation in health care delivery, and the subsequent research that it inspired, documented great variations in rates of hospital admission for certain conditions and rates of surgical procedures between areas that have similar demographic profiles and similar rates of mortality (Wennberg and Gittlesohn, 1973). These findings raise important questions about standards of clinical decision-making and led to a greater focus on the value of spending.

Health economists frequently argue that spending decisions should be based on the net benefit of innovation, not merely whether it increases spending (Cutler et al., 2007; Thomson et al., 2013). A European Observatory Study of health technology assessment in Europe concluded that 'products that provide the most value for investment must be identified and supported' (Sorenson et al., 2009). As others have suggested, using CEA and other techniques to assess the value of care may not be sufficient for making policy decisions (Oliver and Sorenson, 2009). Among other things, using CEA to assess health technology does not address the problem of opportunity cost. In most developed countries, which rely on budgets to limit health care spending, the failure to consider opportunity cost may result in squeezing out existing, but un-assessed, health care technologies and services that are a better value than the 'cost effective' technology included in these assessments. Because the United States does not use a budget to control health care spending, the failure to consider opportunity costs creates a different problem. As long as research and innovation continue producing that kind of value for money, it does not matter that the percentage of gross domestic product spent on health care continues to rise.

While CEA may not be sufficient, it can help to make value judgments about health care spending explicit and its continual rejection by US policy makers is troubling. As Bryan et al. explain, aside from limited use of CEA by the 
Department of Veterans Affairs and the Department of Defense "CEA plays little formal role in evaluating new and/or expensive therapies in the US" (2009: 426). Before the debate over PCORI, there were a few efforts to incorporate the use of CEA into policy at the federal level, but most of these were eliminated or curtailed.

In 1978, Congress established the National Center for Health Care Technology (NCHCT) to conduct health technology assessment and advise the Health Care Financing Administration (HCFA) on Medicare coverage issues. Organized medicine, particularly the American Medical Association, was vocal in its opposition to NCHCT. They argued that the Center's efforts to apply health services research would make cost and cost-effectiveness essential criteria for determining whether medical care is reasonable and necessary (Sorenson et al., 2014: 146). These charges fit well with conservative arguments about limiting the role of government and when Ronald Reagan became president, he eliminated funding for NCHCT. Nearly a decade later, HCFA proposed using CEA to make Medicare coverage decisions. Again, industry opposition led the agency to withdraw the proposal (Sorenson et al., 2013). In 1995, the Agency for Health Care Policy and Research was nearly eliminated by Republican opponents, in part because of the agency's use of CEA (Gray et al., 2002). In 2009, the United States Preventive Services Task Force (USPSTF) issued recommendations regarding the use of mammography among women age 40-49. Although the USPSTF did not base its mammography recommendations on explicit CEA, it concluded that the harms associated with breast cancer screening outweighed the benefits for many younger women (Gusmano and Gray, 2010). As a result, opponents claimed that this was an example of the type of 'rationing' the Obama administration wanted to adopt under health care reform (Gusmano and Gray, 2010).

\section{Why do decision makers resist CEA in the United States?}

To better understand the long-standing political opposition to CEA in the United States, Bryan et al. conducted a workshop with key public and private health care decision makers in California, including representatives from the California Department of Health Services, the insurance industry and business. They found a great deal of support for CEA among these decision makers, but a strong belief that it would be difficult, and perhaps inappropriate, for the private sector to apply these techniques. In particular, leaders from the managed care industry thought that they might lose market share if the public thought they were making coverage decisions on the basis of cost or cost effectiveness. Health plan representatives expressed reluctance to use CEA because "many members of the public perceive them as being interested only in cost savings" and using CEA or even using the language associated with it "could decrease a plan's market share" (Bryan et al., 2009: 434). Other representatives also called for CEA decisions by the government, not because they were concerned with the loss of market share by health plans, but because they thought it would be inappropriate for private 
organizations, many of which are for-profit, to make decisions that depend on assumptions about the public interest (Bryan et al., 2009: 434-435).

Beyond the question of who should be responsible for conducting CEA, the respondents identified a number of important factors that make it difficult to implement CEA in the United States. First, they argued that the long-term perspective of CEA clashed with the short-term perspective of most decision makers.' Second, they expressed concern about the potential for litigation if they decided to rely on CEA for coverage or payment decisions. Third, they argued that the commercial sponsorship of the CEA by the manufacturers of the technologies under review would undermine support for the analysis. Most discussions of the political barriers to CEA focus on how it might limit access to technology. These respondents, in contrast, expressed concern that when CEA relies on data from industry, it could be used to promote spending on technologies that may not provide sufficient value. Nevertheless, concerns about the use of CEA to limit access tend to dominate political objections. Almost half of the respondents indicated that "Americans would not find cost considerations an acceptable basis for coverage decision” (Bryan et al., 2009: 433-434).

\section{Implications for the use of CEA in the United States}

A clear message from the work of Bryan et al. is that, to be politically acceptable in the United States, CEA must overcome its association with the dreaded R word 'rationing.' Efforts to use CEA and other formal evaluation techniques to assess health technology often get caught up in broader political fights about the appropriate role of government. Along with ideological opposition to government interference in the private market, interest group politics are important and CEA is often viewed as a potential threat to technologies that produce a lot of income for those who manufacture and use them.

A challenge that is even more daunting than separating the long-standing association of CEA from setting inappropriate limits, is the need to address normative objections to the values nested within CEA. Respondents to the Bryan et al. study indicated that elected officials may be too focused on cost and budgets in the current fiscal year to appreciate longer-term costs and benefits reflected in CEA, but even if that is not correct, academic critics of CEA and other forms of economic evaluation worry that, in practice, CEA may often fail to account adequately for future costs and benefits or for those that may affect those at a great distance from the region in which the analysis is conducted (Mandel and Gathii, 2006). How to weigh the future is an important question over which there remains significant disagreement.

The observations above underscore the futility of separating CEA from politics and the problem of trust within the US political system. Representatives from the health insurance industry are correct to suggest that the American public does not trust them. When asked about 'health maintenance organizations,' in June 2014, 
only $19 \%$ of Americans claimed to trust them 'a great deal or a lot' (gallup.com/ poll/1597/confidence-institutions.aspx, accessed 1 November 2014). While there are deep concerns that the insurance industry may try to deny coverage of technologies that offer great value to patients, there are also concerns that the pharmaceutical industry is trying to do the opposite. Concerns about industry sponsored information are also not surprising because the same Gallup poll found that only $21 \%$ of Americans trust large businesses 'a great deal or quite a lot' (gallup.com/poll/1597/confidence-institutions.aspx, accessed 1 November 2014).

Unfortunately, the suggestion that CMS take the lead and promote CEA, and the somewhat optimistic conclusion by Bryan et al. that "if CMS were to take the lead on this issue, many would follow quite cheerfully" (2009: 440) ignore the reality of US politics. Public trust of the Congress, the presidency and the executive branch are all at historic lows (gallup.com/poll/1597/confidence-institutions.aspx, accessed 1 November 2014). The polarization of US political parties, and the commitment by Republican members of Congress to undermine anything associated with 'Obamacare,' mean that for the foreseeable future it will be difficult to maintain funding for PCORI's current comparative effectiveness research. Any proposal to adopt more explicit cost-effectiveness criteria and empower CMS to take the lead in doing so will continue to be undermined by the forces described so well in the article by Bryan et al. The continual rejection of CEA in health care is a symptom of the dysfunctional US political system. How to assess health care technologies is merely one of many crucial public decisions the US political system seems incapable of addressing.

\section{References}

Brown, C. B. (2009), 'SEIU: health care ad “unfit to air”'. Politico, April 30 http://www. politico.com/news/stories/0409/21964.html [10 November 2014].

Bryan, S., S. Sofaer, T. Siegelberg and M. Gold (2009), 'Has the time come for cost-effectiveness analysis in US health care?', Health Economics, Policy and Law, 4: 425-443.

Cutler David, M., G. Long, E. R. Berndt, J. Royer, A. Fournier, A. Sasser and P. Cremieux (2007), 'The value of antihypertensive drugs: a perspective on medical innovation', Health Affairs, 26(1): 97-110.

Demko, P. (2014), 'Where will Obama draw the line on GOP bills to roll back reform?' Modern Healthcare, November 8 http://www.modernhealthcare.com/article/20141108/ MAGAZINE/311089988 [9 November 2014].

Gusmano, M. K. and B. H. Gray (2010), 'Evidence and fear: navigating the politics of evidence based medicine', Academy Health Reports, 38: 1-5.

Mandel, G. N. and T. Gathii (2006), 'Cost-benefit analysis versus the precautionary principle: beyond cass Sunstein's laws of fear', University of Illinois Law Review, 5: 1037-1080.

Oliver, A. and C. Sorenson (2009), 'The limits and challenges to the economic evaluation of health technologies', in J. Costa-Font and A. McGuire (eds), Economics of Innovation and New Health Care Technologies, Oxford: Oxford University Press.

Sorenson, C., M. Drummond and P. Karavos (2009), Ensuring Value for Money in Health Care: The Role of Health Technology Assessment in the European Union, Observatory Series No. 11. Copenhagen: WHO Regional Office for Europe. p. xiii. 
Sorenson, C., M. K. Gusmano and A. J. Oliver (2014), 'The politics of comparative effectiveness research: lessons from recent history', Journal of Health Politics, Policy And Law, 39(1): 139-170.

Thomson, S., L. Schang and M. E. Chernew (2013), 'Value-based cost sharing in the united states and elsewhere can increase patients' use of high-value goods and services', Health Affairs, 32: 704-712.

Wennberg, J. E. and A. Gittlesohn (1973), 'Small-area variations in health care delivery', Science, 182: 1102-1108. 